\title{
A New Specific Sequence to Distinguish B.canis From Other Brucella by PCR
}

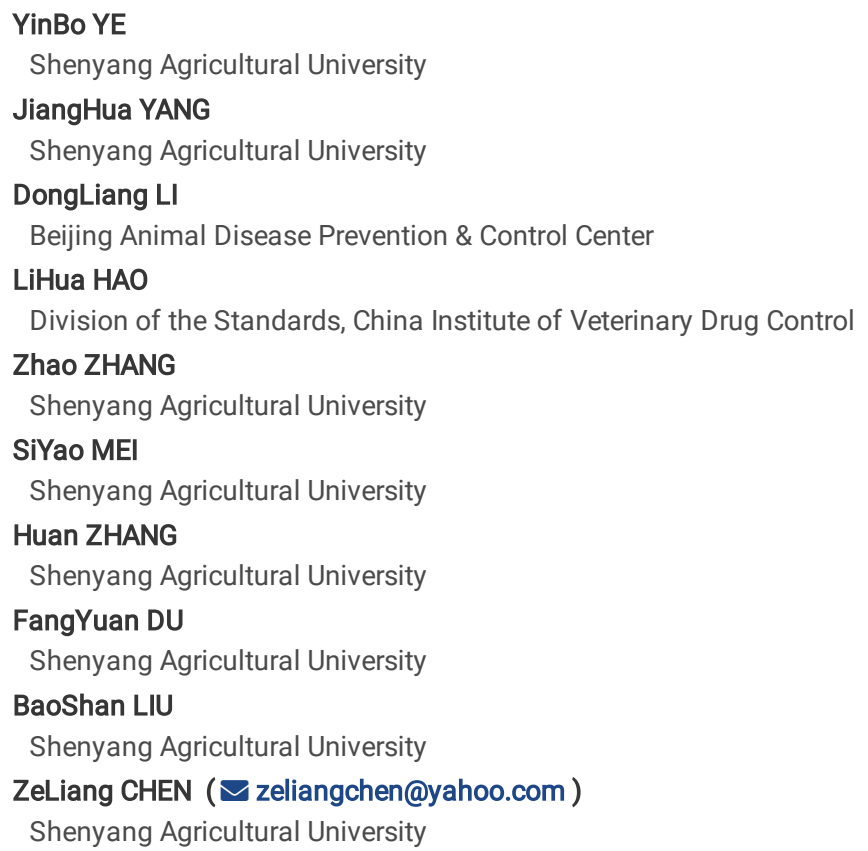

Keywords: B.canis, Brucellosis, other Brucella, PCR, specific sequence

Posted Date: April 22nd, 2021

DOI: https://doi.org/10.21203/rs.3.rs-413085/v1

License: (9) (7) This work is licensed under a Creative Commons Attribution 4.0 International License. Read Full License 


\section{Abstract}

Background: Brucellosis is a zoonotic disease worldwide. The increasing number of pet dogs has raised new risk of people getting canine brucella with absent or mild symptom. Besides, the canine brucellosis can be caused by other brucella species, so their infection could be omitted by the PCR method. The present PCR methods can only detect canine brucella, by which cases infected with other brucella would appear negative. It's an urge to develop a specific PCR assay for detecting canine Brucellosis, Whether the pathogen was B.canis or any other Brucella.

Resaults: a differential sequence of B.canis were found by genome comparison analysis and were analyzed by BLAST. Then a PCR method was established using specific primers in the sequence and tested for clinical application. It could detect canine brucellosis caused by B.canis or other Brucella species with 310-bp and 413-bp product, respectively. The developed PCR method had specificity for non-brucella and a sensitivity of 100 copies of Brucella DNA. The detection accuracy verified with spiked samples was $95.5 \%$ (21/22) for B.canis and 100\% (22/22) for other brucella.

Conclusions: The study found a specific sequence of B.canis and developed a PCR detection method to detect canine brucellosis caused by B.canis or other Brucella species. The method established in this study will more comprehensively detect the pathogen of canine brucellosis and provide important methods and means for preventing and controlling this disease.

\section{Introduction}

The genus Brucella is one kind of the most widespread bacteria, inducing Brucellosis. They have been gradually expanded by discovering strains from wildlife animal species, such as amphibians and fish[1]. Four major pathogenic Brucella species causing disease in humans are B.abortus (cattle, buffalo), B.melitensis (goats, sheep, camels), B.suis (pigs), and B.canis (Dogs)[2]. Annually more than 500,000 new brucellosis cases are diagnosed worldwide[3].

As the primary pathogen of brucellosis in dogs, B.canis can be transmitted to humans by infected dogs or their secretions. Unlike the infection by other Brucella species, the infection symptoms with B.canis are absent or mild[4]. However, endocarditis or meningitis may develop in some cases[5]. So, the human infection of Brucella canine remains a concern, especially as pets are being raised in large numbers.

The isolation and culture are the most accurate method for brucellosis detection and species identification by amino sugar quinovosamine assay[6]. However, they are time-consuming and need to be performed in a laboratory with biosafety level III. Its effectiveness is affected by the infected animal's bacteremia level[7]. Molecular biological detection technology has the characteristics of safety and reliability, high sensitivity, strong specificity and simple operation, and has begun to be popularized and applied to detect Brucella $[8,9]$.

Now there were a variety of PCR methods for detecting canine Brucella[10, 11], such as bruce-ladder[11] and multilocus variable-number tandem-repeat (VNTR) analysis (MLVA) procedures[12]. Most of them distinguished B.canis by multiple amplification products, which required a lot of time to remember each Brucella species' amplified bands. More to the point, it needed high quality and concentration genomic DNA, limiting the choice of clinical specimens[13].

In 2014, a PCR method for only detecting B.canis was established based on the 12bp deletion of BCAN_B0548 region $\nabla 530056$ site冈in chromosome II of B.canis ATCC 23365[13]. However, it cannot detect other Brucella species and omit probably the brucella infection by other Brucella species[14].

In this study, we found a specific sequence of B.canis by comparing the genomes of B.canis and B.melitensis and BLASTing in the GeneBank, which is reverse complementary in other Brucella species. PCR of three primers designed based on this sequence can specifically detect canine Brucella and other Brucella, which simplified the clinical identification and diagnosis of canine brucellosis and is very conducive to its prevention and control to reduce human infection.

\section{Materials And Methods}

\section{Strains and DNA extraction}

All the strains used in this experiment were listed in Table 1. The DNA of B.abortus strains 2308, B.melitensisbv. 1 str. $16 \mathrm{M}$ and B.canis strain RM6/66 were donated by the China Institute of Veterinary Drug Control. B.melitensis strains M5, B.abortus strain A19 and B.suis strain S2 were purchased from Tecon Biology Co. Ltd, Xinjiang. Caine Vanguard ${ }^{\circledR}$ Plus 5-CVL vaccine and feline Fel-O-Vax® PCT vaccine (Zoetis, USA) were purchased from a local pet hospital. Other common bacterial strains are preserved in this laboratory. Their genetic DNA was extracted with MiniBEST Bacteria Genomic DNA Extraction Kit (Takara, Dalian, China) According to the manufacturer's instructions and measured with an ultraviolet spectrophotometer. The copies of the genome were counted online on the website http://scienceprimer.com/copy-number-calculator-for-realtime-pcr. The extracted DNA was stored at -20 ${ }^{\circ} \mathrm{C}$ until use. $86 \mathrm{Cannie}$ blood samples were collected in the pet hospitals in Shenyang. Their DNA was extracted with the MiniBEST Whole Blood Genomic DNA Extraction Kit (Takara, Dalian, China) and stored at $-20^{\circ} \mathrm{C}$. Taq PCR MasterMix was purchased from Vazyme Biotech Co., Ltd, Nanjing, China.

\section{Screening of the specific sequence of B.canis}

Genome sequences of B.canis and other species were downloaded from the NCBI database. Sequences were analyzed by the multiple genome alignment software Mauve 20150226 (The Darling lab at the University of Technology Sydney). The list of gaps and single nucleotide polymorphisms (SNPs) of alignment results of chromosomes 1 and 2 were exported. BLAST was used to compare the candidate gaps of the two strains for the specific differential sequences of the B.canis. The potential sequences in both genomes of B.canis and B.melitensis were aligned by the software DNAMAN 7 .

primer design

Page 2/10 
Primer-blast on the NCBI website was used to design the primers and make the appropriate adjustments to obtain specific primers. The designed primers were synthesized by Sangon Biotech Co., Ltd (Shanghai, China).

\section{Optimization of the PCR Amplification condition}

In the PCR reaction, 2xTaq PCR MasterMix ten $\mu \mathrm{L}$, each primer $(10 \mu \mathrm{M}) 1 \mu \mathrm{L}$ and five $\mu \mathrm{L}$ water were mixed in the $200 \mu \mathrm{L}$ PCR tube. Then one $\mu \mathrm{L}$ Brucella DNA template or one $\mu \mathrm{L}$ distilled water were added as templates or negative control. The PCR amplification conditions were as follows: pre-denaturation at $94^{\circ} \mathrm{C}$ for 5 minutes, then 35 cycles at $95^{\circ} \mathrm{C}$ for $15 \mathrm{~s}, 60^{\circ} \mathrm{C}$ for $15 \mathrm{~s}$ and $72^{\circ} \mathrm{C}$ for $30 \mathrm{~s}$, followed by a final extension at $72{ }^{\circ} \mathrm{C}$ for 10 min. The PCR amplification products were identified by electrophoresis in $1.5 \%$ agarose gel.

For determining better amplification conditions, PCR reaction was optimized by annealing in temperature $60^{\circ} \mathrm{C}, 64^{\circ} \mathrm{C}, 68^{\circ} \mathrm{C}, 72^{\circ} \mathrm{C}$. The optimum annealing temperature was determined according to the stray band's existence and the amplified band's brightness.

\section{Specificity and sensitivity of the assay}

The DNA template was diluted from $10^{4}$ to 1 copies/ $\mu \mathrm{L}$ with sterilized distilled water. One $\mu \mathrm{L}$ diluted DNA was used as the template in PCR amplification. Electrophoresis was performed to determine the sensitivity of the PCR assay.

For verifying the PCR assay's specificity, DNAs of other Brucella strains and bacteria and vaccine in Table 1 were used as templates for PCR amplification under the best annealing temperature. The amplification products were analyzed in a $1.5 \%$ electrophoresis gel and observed under ultraviolet light.

\section{Detection and verification}

For evaluating the clinical efficacy of the established PCR method, 66 DNAs from B.canis-negative blood samples were spiked double-blindly with the DNA of B.canis and other Brucella were tested. The number of samples spiked with positive brucella DNAs was listed in Table 3. The spiked samples were detected by the developed PCR and the results were analyzed by $1.5 \%$ electrophoresis gel.

\section{Results}

\section{Analysis of the genome}

Genome sequences of B.canis strain RM6/66 (NZ_CP007758.1, NZ_CP007759.1) and B.melitensisbv. 1 str. 16M (NZ_CP007763.1, NZ_CP007762.1) strains were downloaded from the NCBI database. Chromosome I (NZ_CP007758.1, NZ_CP007763.1) and chromosome II (NZ_CP007759.1, NZ_CP007762.1) sequences of B.canis strain RM6/66 and B.melitensisbv. 1 str. $16 \mathrm{M}$ were analyzed by the multiple genome alignment software Mauve 20150226 , respectively. Compared with $16 \mathrm{M}$, both chromosomes I and II of RM6/66 genome had gene rearrangement (Fig. 1A, 1B), but the frequency of chromosome II rearrangement was higher than that of chromosome $\mathrm{I}$.

The list of gaps and single nucleotide polymorphisms (SNPs) of alignment results of chromosomes 1 and 2 were exported from the mauve program. There are 204 gaps, 231 inserts and 5143 SNPs in chromosome I, while there are 140 gaps, 169 inserts and 3113 SNPs in chromosome II (Fig. 1C). Chromosome 1 is more diverse than Chromosome 2.

BLAST was used to compare the candidate gaps of the two strains for the specific differential sequences of the B.canis. It was found that a $132 \mathrm{bp}$ gap at 943403rd site on B.canis chromosome 1 corresponds to the same gap at 303367th site on B.melitensis chromosome 1 (Fig.2A). By aligning, the gap sequence in both genomes of B.canis and B.melitensis has a very low similarity (Fig.2B). Further analysis found that they are reverse complementary sequences (Fig.2C). The gap and adjacent sequence's alignment showed good specificity in BLAST, only having a high similarity and high score with B.canis (Fig.2D). It was suggested that this sequence is a characteristic of B.canis and can be potential for identifying B.canis.

\section{Primer design}

Three primers (Table 2) in the region $943226-943581$ of chromosome I of B.canis strain RM6/66 were designed by the online primers design programs PrimerBLAST (https://blast.ncbi.nlm.nih.gov/Blast.cgi). The position of each primer was shown in figure 2C. PCR with these three primers should amplify $310 \mathrm{bp}$ and 413bp fragments using B.canis and other Brucella species as templates, respectively.

\section{Optimization of the PCR Amplification condition}

For determining better amplification, annealing temperature in PCR was optimized. The results showed that evident PCR bands could be seen at annealing temperature $60{ }^{\circ} \mathrm{C}$ to $68^{\circ} \mathrm{C}$ (Fig.3A). However, the amplification band at $64{ }^{\circ} \mathrm{C}$ was the brightest and the amplification effect was the highest. So, $64{ }^{\circ} \mathrm{C}$ was used as the reaction temperature in the subsequent specificity and sensitivity tests.

\section{The sensitivity of the assay}

For determining the sensitivity of the PCR method, it was executed using the gradient dilution DNA of B.canis strain RM6/66 as a template. The results showed that the reaction solution with $10^{4}-10^{2}$ copies of DNA showed PCR amplification bands in the electrophoresis (Fig. 3B), indicating that the established PCR assay could be detected a minimum of 100 copies of Brucella DNA.

\section{The specificity of the assay}


Respectively using DNA of the B.canis strain RM6/66, strain A19, B.suis strain S2, B.melitensis strain 16M, B.abortus strain 2308, B.suis strain 1330, Vanguard ${ }^{\circledR}$ Plus 5-CVL vaccine, Fel-O-Vax ${ }^{\circledR}$ PCT vaccine (Zoetis, USA) and other bacterial as a template, PCR assay was conducted with best annealing temperature $64^{\circ} \mathrm{C}$. The results show that the reaction product with the B.canis DNA and other brucella DNA existed a specific $310 \mathrm{bp}$ and $413 \mathrm{bp}$ band in the electrophoresis, respectively (Fig. 3C). At the same time, the reaction products with other DNA are no specific bands. It showed that the established PCR detection method had excellent specificity. Meantime, it can not only detect Brucella but also distinguish B.canis from other Brucella species.

\section{Detection and verification}

For verifying the efficacy of the PCR assay, 66 DNAs of clinical blood samples spiked randomly with the DNA of B.canis or other Brucella were tested (Fig. 4). The result showed that the developed assay detected 43 of the 44 spiked samples, with a detection accuracy of $95.5 \%$ (21/22) for B.canis and $100 \%$ (22/22) for other Brucella, respectively (Table 3). These results indicated that the developed assay had a good feature for the detection of B.canis or other Brucella.

\section{Discussion}

The current study aimed to develop a specific PCR assay for detecting canine Brucellosis, Whether the pathogen was B.canis or any other Brucella. Firstly, a differential sequence of B.canis was found by genome comparison analysis and was analyzed by BLAST. Then a differential PCR method was established using specific primers in the sequence and tested for clinical application. The developed PCR method had good specificity and sensitivity and can be used to detect canine brucellosis caused by various Brucella, which is conducive to the prevention and control of canine brucellosis and the protection of human safety.

With the development of sequencing, databases, and networking technologies, vast amounts of genomic and sequence data are now available at individual terminals. How to make good use of these data has become an essential aspect of improving research efficiency. Desktop or web bioinformatics software addresses this problem very well. Multiple Genome Alignment Software Mauve can quickly analyze rearrangements, insertions, deletions and changes between genome sequences and determine the differences between genes from a macro and micro perspective[15, 16]. BLAST is a general alignment procedure that compares sequences similar to target sequences in Genebank databases to discover target sequences' specificity[17]. The combination of the two software can be used to screen target sequences. Primer-Blast is a procedure for Primer design and comparison, which can effectively analyze the specificity of primers [18]. The combined use of these software can effectively improve the specificity and success rate of PCR, which is widely used[19]. The same process was used in this study and satisfactory results were obtained.

Molecular biological detection of Brucella is abundant[9, 20, 21]. However, there were a few PCR methods for detecting canine Brucella[10, 11]. Bruce-ladder assay is a common method[11], which distinguished B.canis by multiple amplification products. However, it required much time to remember each brucella species' amplified bands and high quality and concentration genomic DNA limiting clinical specimens' choice[13]. A PCR method for only detecting B.canis was established in 2014, which was based on the $12 \mathrm{bp}$ deletion of chromosome II of B.canis ATCC 23365 and had a detection limit of $3 \times 10^{3}$ colony-forming units (CFU)[13]. However, the canine brucellosis can be caused by other Brucella species[14], so their infection could be omitted by the PCR method. In this study, a B.canis specific sequence was found, which showed reverse complementary in other Brucella. The established PCR based on the specific sequence

can detect B.canis and other Brucella species simultaneously without amplifying other common bacteria and viruses. Its detection limit was 100 copies of the B.canis genome, higher than the above PCR method.The PCR assay was evaluated with spiked DNA samples. Of 66 DNA samples, the accuracy was $97.5 \%$ (43/44). It might be a low concentration that one sample was identified as a false negative. This work could give a more convenient verification for PCR method without comparative standard methods due to the spiked samples.

B.canis mostly cause canine brucellosis. However, other commonly exposed brucella strains, such as B.suis, B.abortus and B.melitensis, can also cause it[14]. Unlike B.canis, they have high pathogenicity to humans. People who contact with dogs infected these Brucella are at high risk. Therefore, it is necessary to strengthen the detection of brucellosis. The method established in this study will more comprehensively detect the pathogen of canine brucellosis and provide important methods and means for preventing and controlling the disease.

In conclusion, the study found a specif sequence of B.canis and developed a PCR detection method to detect canine brucellosis caused by B.canis or other Brucella species. It will serve for the prevention and control of canine brucellosis to reduce human brucellosis.

\section{Declarations}

\section{Ethics approval and consent to participate}

The experiment was licensed by the Institutional Animal Care and Use Committee of Shenyang Agricultural University (IACUC Issue No.2020070307). Informed consent was obtained from owners for animal sample collection. All methods were carried out in accordance with relevant guidelines and regulations.

\section{Consent for publication}

Not applicable.

\section{Availability of data and materials}

The datasets generated and/or analysed during the current study are available in the NCBI

database(https://www.ncbi.nlm.nih.gov/nuccore/NZ_CP007758.1;https://www.ncbi.nlm.nih.gov/nuccore/NZ_CP007759.1;https://www.ncbi.nlm.nih.gov/nucc

\section{Competing interests}


The authors declare that they have no competing interests.

\section{Funding}

This work was supported by National Key Research and Development Program Projects of China (2017YFD0500901, 2017YFD0500305), the National Key Program for Infectious Diseases of China (2018ZX10101002-002), the State Key Program of National Natural Science of China (U1808202), NSFC International (regional) cooperation and exchange program (31961143024), Major science and technology projects of Inner Mongolia of China.

\section{Authors' contributions}

BS LIU and ZL CHEN conceived the study. YB YE and JH YANG directed the study. DL LI and LH HAO analyzed the data. Z ZHANG and SY MEI performed the PCR. H ZHANG and FY DU wrote the manuscript.

\section{References}

1. Cloeckaert A, Vergnaud G, Zygmunt MS. Omp2b Porin Alteration in the Course of Evolution of Brucella spp. Front Microbiol. 2020;11:284. https://doi.org/10.3389/fmicb.2020.00284.

2. Kyebambe PS. Acute brucella meningomyeloencephalo-spondylosis in a teenage male. Afr Health Sci. 2005;5(1):69-72-

3. Pisarenko SV, Kovalev DA, Volynkina AS, Ponomarenko DG, Rusanova DV, Zharinova NV, Khachaturova AA, Tokareva LE, Khvoynova IG, Kulichenko AN. Global evolution and phylogeography of Brucella melitensis strains. BMC Genomics. 2018;19(1):353. https://doi.org/10.1186/s12864-018-4762-2.

4. Yüksekkaya S, Aras Z, U?an US. Investigation of Brucella canis Seroprevalence in Brucellosis Suspected Cases. Mikrobiyol Bul. 2013;47(1):152-7-.

5. Sayan M, Erdenli? S, Etiler N. Investigation of Brucella canis seropositivity by in-house slide agglutination test antigen in healthy blood donors. Mikrobiyol Bul. 2011;45(4):655-63-.

6. Ohishi K, Abe E, Amano M, Miyazaki N, Boltunov A, Katsumata E, Maruyama T. Detection of serum antibodies to Brucella in Russian aquatic mammals. J Vet Med Sci. 2018:-

7. Camargo-Castañeda AM, Stranahan LW, Edwards JF, Garcia-Gonzalez DG, Roa L, Avila-Granados LM, Hensel ME, Arenas-Gamboa AM. Characterization of epididymal and testicular histologic lesions and use of immunohistochemistry and PCR on formalin-fixed tissues to detect Brucella canis in male dogs. $J$ Vet Diagn Invest. 2021:1040638720986883. https://doi.org/10.1177/1040638720986883.

8. Ren H, Yang M, Zhang G, Liu S, Wang X, Ke Y, Du X, Wang Z, Huang L, Liu C, Chen Z. Development of a rapid recombinase polymerase amplification assay for detection of Brucella in blood samples. Mol Cell Probes. 2016;30(2):122-4. https://doi.org/10.1016/j.mcp.2016.02.007.

9. Bhat IA, Mashooq M, Kumar D, Varshney R, Rathore R. Development of probe based real time loop mediated isothermal amplification for detection of Brucella. J Appl Microbiol. 2018:-

10. Hinić V, Brodard I, Thomann A, Cvetnić Z, Makaya PV, Frey J, Abril C. Novel identification and differentiation of Brucella melitensis, B. abortus, B. suis, B. ovis, B. canis, and B. neotomae suitable for both conventional and real-time PCR systems. J Microbiol Methods. 2008;75(2):375-8.

https://doi.org/10.1016/j.mimet.2008.07.002.

11. López-Goñi I, García-Yoldi D, Marín CM, de Miguel MJ, Barquero-Calvo E, Guzmán-Verri C, Albert D, Garin-Bastuji B. New Bruce-ladder multiplex PCR assay for the biovar typing of Brucella suis and the discrimination of Brucella suis and Brucella canis. Vet Microbiol. 2011;154(1-2):152-5. https://doi.org/10.1016/j.vetmic.2011.06.035.

12. Daugaliyeva A, Sultanov A, Usserbayev B, Baramova S, Modesto P, Adambayeva A, Acutis PL, Peletto S. Genotyping of Brucella melitensis and Brucella abortus strains in Kazakhstan using MLVA-15. Infect Genet Evol. 2018;58:135-44-.

13. Kang SI, Lee SE, Kim JY, Lee K, Kim JW, Lee HK, Sung SR, Heo YR, Jung SC, Her M. A new Brucella canis species-specific PCR assay for the diagnosis of canine brucellosis. Comp Immunol Microbiol Infect Dis. 2014;37(4):237-41. https://doi.org/10.1016/j.cimid.2014.07.003.

14. Philippon A, Roumy B, Renoux G. [A case of canine brucellosis due to Brucella abortus]. Bull Acad Vet Fr. 1969;42(9):923-8.

15. Darling AC, Mau B, Blattner FR, Perna NT. Mauve: multiple alignment of conserved genomic sequence with rearrangements. Genome Res. 2004;14(7):1394-403. https://doi.org/10.1101/gr.2289704.

16. Rissman Al, Mau B, Biehl BS, Darling AE, Glasner JD, Perna NT. Reordering contigs of draft genomes using the Mauve aligner. Bioinformatics. 2009;25(16):2071-3. https://doi.org/10.1093/bioinformatics/btp356.

17. Camacho C, Coulouris G, Avagyan V, Ma N, Papadopoulos J, Bealer K, Madden TL. BLAST+: architecture and applications. BMC Bioinformatics. 2009;10:421. https://doi.org/10.1186/1471-2105-10-421.

18. Ye J, Coulouris G, Zaretskaya I, Cutcutache I, Rozen S, Madden TL. Primer-BLAST: a tool to design target-specific primers for polymerase chain reaction. BMC Bioinformatics. 2012;13:134. https://doi.org/10.1186/1471-2105-13-134.

19. Baoshan L, Yinbo Y, Jingbo Z, Yi Z, Jianghua Y, Dawei C, Chi M, Donghai Y, Bohan Y, Rongnian Z, Sheng F, Jun Z, Han X, Chen Z. Combined nucleic acid assays for diagnosis of A19 vaccine-caused human brucellosis. Transbound Emerg Dis. 2020. https://doi.org/10.1111/tbed.13685.

20. Pal D, Boby N, Kumar S, Kaur G, Ali SA, Reboud J, Shrivastava S, Gupta PK, Cooper JM, Chaudhuri P. Visual detection of Brucella in bovine biological samples using DNA-activated gold nanoparticles. PLoS One. 2017;12(7):e0180919-0180919.

21. Hasanzadeh M, Babaie P, Mokhtarzadeh A, Hajizadeh N, Mahboob S. A novel DNA based bioassay toward ultrasensitive detection of Brucella using gold nanoparticles supported histidine: A new platform for the assay of bacteria in the cultured and human biofluids with and without polymerase chain reactions (PCR). Int J Biol Macromol. 2018;120(Pt A):422-30-. 
Tables

Table 1 Bacteria strains tested in this study.

\begin{tabular}{|c|c|c|c|}
\hline \multicolumn{2}{|l|}{ Bacterial species } & Strain & Source \\
\hline \multicolumn{2}{|l|}{ Brucella abortus } & A19 & Tecon Biology CO. Ltd \\
\hline \multicolumn{2}{|l|}{ Brucella suis } & S2 & Tecon Biology CO. Ltd \\
\hline \multicolumn{2}{|l|}{ Brucella melitensis } & M5 & Tecon Biology CO. Ltd \\
\hline \multicolumn{2}{|l|}{ Brucella canis } & $\mathrm{RM} 6 / 66$ & CVCC \\
\hline \multicolumn{2}{|l|}{ Brucella abortus } & 2308 & CVCC \\
\hline \multicolumn{2}{|l|}{ Brucella suis } & 1330 & CVCC \\
\hline \multicolumn{2}{|l|}{ Brucella melitensis } & $16 \mathrm{M}$ & CVCC \\
\hline \multicolumn{2}{|l|}{ Salmonella enteritidis } & CVCC3949 & CVCC \\
\hline \multicolumn{2}{|l|}{ Shigella dysenteriae } & CVCC1881 & CVCC \\
\hline \multicolumn{2}{|l|}{ Pasteurella multocida } & CVCC1676 & CVCC \\
\hline \multicolumn{2}{|l|}{ Streptococcus hemolyticus } & CVCC1886 & CVCC \\
\hline \multicolumn{2}{|l|}{ Clostridium perfringens type $C$} & CVCC1147 & CVCC \\
\hline \multicolumn{2}{|l|}{ Staphylococcus aureus } & CVCC4098 & CVCC \\
\hline \multicolumn{2}{|l|}{ Proteus mirabillis } & CVCC1969 & CVCC \\
\hline \multicolumn{2}{|l|}{ Candida albicans } & CVCC3597 & CVCC \\
\hline \multicolumn{2}{|l|}{ Streptococcus pyogenes } & CVCC1930 & CVCC \\
\hline \multicolumn{2}{|l|}{ Streptococcus pneumoniae } & CVCC4105 & CVCC \\
\hline \multicolumn{2}{|l|}{ Campylobacter jejuni } & CVCC3883 & CVCC \\
\hline \multicolumn{2}{|l|}{ listeria monocytogenes } & CVCC3763 & CVCC \\
\hline \multicolumn{2}{|l|}{ pseudomonas aeruginosa } & CVCC3795 & CVCC \\
\hline \multicolumn{2}{|l|}{ Escherichia coli } & $\mathrm{DH} 5 \mathrm{a}$ & Our laboratory \\
\hline \multirow[t]{8}{*}{ Vanguard $\AA^{\circledR}$ Plus 5 -CVL vaccine } & Canine distemper virus & Snyder Hill & \multirow[t]{8}{*}{ Zoetis, USA } \\
\hline & Canine adenovirus type 1 & & \\
\hline & Canine adenovirus type 2 & Manhattan & \\
\hline & Canine parainfluenza virus & NL-CPI-5 & \\
\hline & Canine parvovirus & NL-35-D & \\
\hline & Canine coronavirus & NL-18 & \\
\hline & Leptospira canicola & C-51 & \\
\hline & Leptospira icterohemorrhaiae & NADL & \\
\hline \multirow[t]{3}{*}{ Fel-O-Vax® PCT vaccine } & Feline Rhinotracheitis virus & 605 & \multirow[t]{3}{*}{ Zoetis, USA } \\
\hline & Feline Calicivirus & 255 & \\
\hline & Feline Panleukopenia virus & $\mathrm{Cu}-4$ & \\
\hline
\end{tabular}

CVCC: Chinese veterinary Culture collection center.

Table 2 Primers and probes used in this study

\begin{tabular}{|lllll|}
\hline Primer name & Sequence & Length & Tm & Amplicon length \\
\hline BSU1 & GCAGGTCGTTACCGTCGATC & 20 & 60.86 & \\
\hline BCD & CAATATCCGCAACGCCTCTTG & 21 & 60.00 & 310 \\
\hline BSD2 & CATCAAGCCGCATCGCAGC & 19 & 62.80 & 413 \\
\hline
\end{tabular}


Table 3 Detection of spiked DNA samples from clinical blood specimen

\begin{tabular}{|llll|}
\hline & Spiked number & Developed PCR & Accuracy \\
\hline B.canis & 22 & 21 & $95.5 \%$ \\
\hline Other brucella & 22 & 22 & $100 \%$ \\
\hline Negative & 22 & 22 & $100 \%$ \\
\hline Total & 66 & 65 & $98.8 \%$ \\
\hline
\end{tabular}

\section{Figures}

A
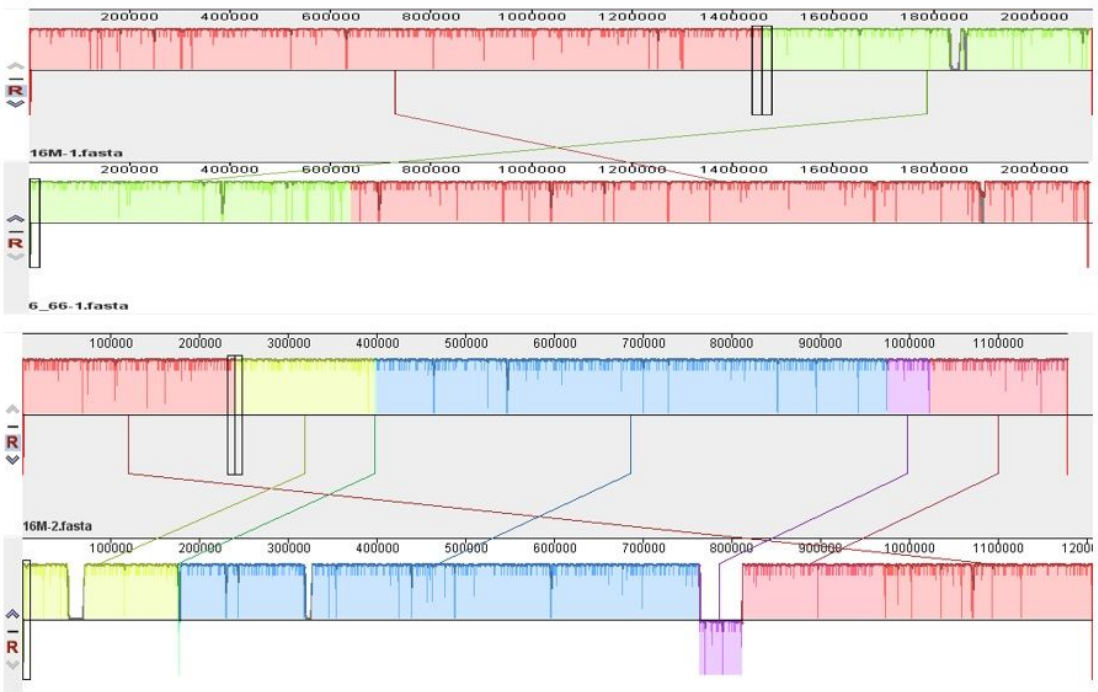

6.66.2fasta

C

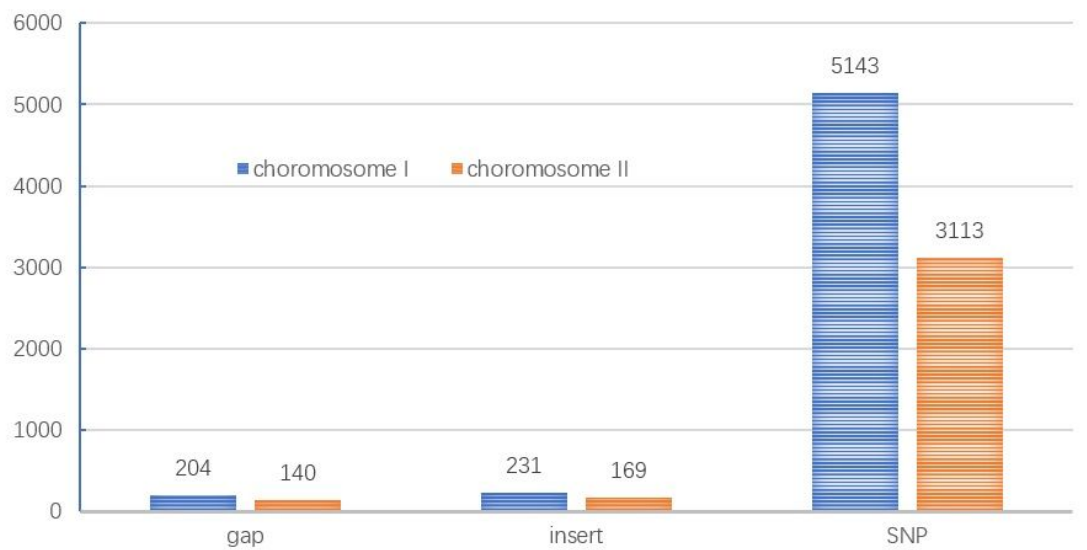

\section{Figure 1}

genome analysis of the B.canis strain RM6/66 and B.melitensis 2308. A. the alignment of the chromosome I. B. the alignment of the chromosome II. C. differential statistics of the B.canis strain RM6/66 genomes in comparison to B.melitensis 2308 genome. 


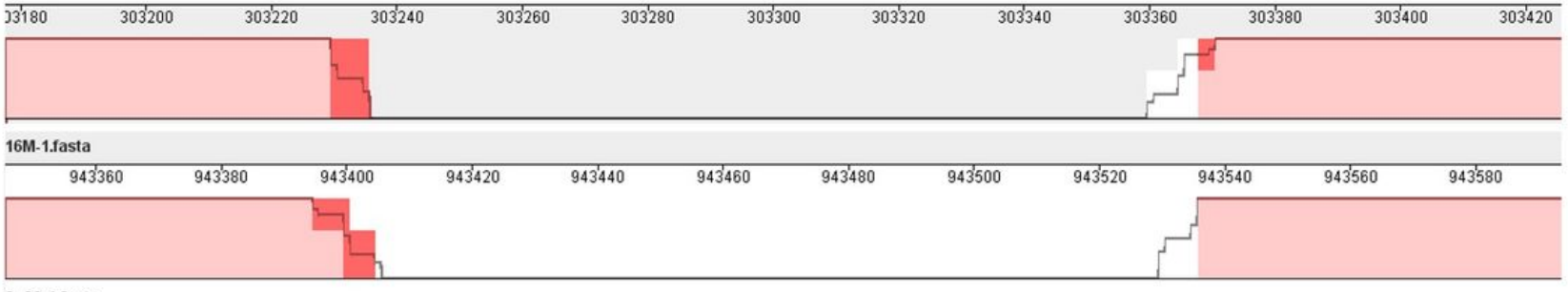

\section{6_66-1.fasta}

B B.canis

B.melitensis

CGCCGGAGGGCAGGTCGTTACCGTCGATCTTGTTCCAGAATTCCACCTGATAAATCTGCGTGGCGGTTGCCTGCGTCAGTTCCTTCACATCCTGCGGCGATACCTGCCGTCCTTCCCATG CGCCGGAGGGCAGGTCGTTACCGTCGATCTTGTTCCAGAATTCCACCTGATAAATCTGCGTGGCGGTTGCCTGCGTCAGTTCCTTCACATCCTGCGGCGATACCTGCCGTCCTTCCCATG

B. canis

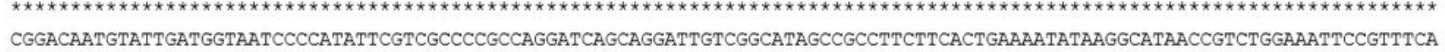

B.melitensis CGGACA.ATGTATTGATGGTAATCCCCATATTCGTCGCCCCGCCAGGATCAGCAGGATTGTCGGCATAGCCGCCTTCTTCACTGAAAA.ATATAAGGCATAACCGTCTGGAAATTCCGTTTCA

\section{B. canis} ******************************************************************************************************************************

B.melitensis TAATTTGCCCCTACTTTAGATTTTGATAAATTATTGAATACTACCGCAGCGCGC-CGCGCAAGA--GGCGTTGCGGATATTGTCC-GCTTTTTTCCGAATTACCTGCCCTGCCGAGGCCG TAATTTGCCCCTACTTTAGATTTTGATAAATTATTGAATACTAdACCTATACGTGTATGGTAGCACGGCGCTCCGGCAAGGGAATAGGGGTGTTCCCAACGGCCTCGGCAGGGCAGGTAA

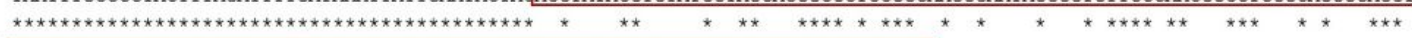

B.canis TTGGGAACACCCTATTCCCTTGCCGGAGCCCGTGCTACCATACACGTATAGGTAG-GGCTTGATGCGTTTATCTCT GGACGGCTTACAGGCAGGCAATCGTGAATTCGGAATCTTCG B.melitensis ITCGGAAAAAAGCGGA-CAATATCCGCAACGCCT--CTTGCGCG-GCGCGCTGCGAGCGGCTTGATGCGTTTATCTCI] GGACGGCTTACAGGCAGGCAATCGTGAATTCGGAAATCTTCG $* * * * * * * * * * * * * * * * * \quad * * \quad * \quad * * \quad * * * * * * * * * * * * * * * * * * * * * * * * * * * * * * * * * * * * * * * * * * * * * * * * * * * * * * * * * * * * * * * * * * *$

C B.canis

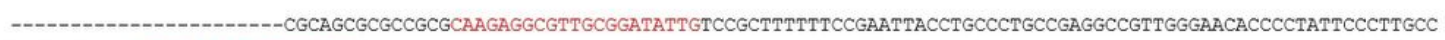
B.melitensis RC AGAGATAAACGCATCAAGCCGCTCGCAGCGCGCCGCGCAAGAGGCGTTGCGGATATTGTCCGCTTTTTTCCGAATTACCTGCCCTGCCGAGGCCGTTGGGAACACCCCTATTCCCTTGCC

B.canis GGagCGCCGTGCTACCATACACGTATAGGTAGgGCTTGATGCGTTTATCTCT

B.melitensis RC GGAGCGCCGTGCTACCATACACGTATAGGT-

D

D Brucella canis strain 2009013648 chromosome 1 sequence

Drucella canis strain 2009004498 chromosome 1. complete sequence

Drucella canis strain RM6/66 chromosome 1. complete sequence

Drucella canis strain SVA13 chromosome 1. complete sequence

D Brucella canis str. Oliveri chromosomel, genome

- Brucella canis ATCC 23365 chromosomel. complete sequence

- Brucella canis strain GB1 chromosome 1. complete sequence

D Brucella canis strain 2010009751 chromosome 1. complete sequence

Drucella canis HSKA52141 chromosome 1, complete sequence

Drucella suis strain 2011017258 chromosome 1 sequence

Brucella suis strain 2004000577 chromosome 1, complete sequence

Brucella suis 019 chromosome 1 sequence

Brucella suis strain ZW046 chromosome 1.complete sequence

Brucella suis strain ZW043 chromosome 1. complete sequence

Brucella suis strain BSP chromosome 1. complete sequence

\begin{tabular}{|c|c|}
\hline Scientific Name & Common Name \\
\hline Brucella canis & Brucella canis \\
\hline Brucella canis & Brucella canis \\
\hline Brucella canis & Brucella canis \\
\hline Brucella canis & Brucella canis \\
\hline Brucella canis str. Oliveri & Brucella canis str. Oliver \\
\hline Brucella canis ATCC 23365 & Brucella canis ATCC 23365 \\
\hline Brucella canis & Brucella canis \\
\hline Brucella canis & Brucella canis \\
\hline Brucella canis HSK A52141 & Brucella canis HSK A52141 \\
\hline Brucella suis & Brucella suis \\
\hline Brucella suis & Brucella suis \\
\hline Brucella suis 019 & Brucella.suis 019 \\
\hline Brucella suis & Brucella suis \\
\hline Brucella.suis & Brucella suis \\
\hline Brucella suis & Brucella suis \\
\hline
\end{tabular}

$\begin{array}{cccc}\text { Taxid Max } & \text { Total Query } \\ \text { Score Score Cover }\end{array}$ $\begin{array}{llll}36855 & 1284 & 1284 & 100 \%\end{array}$ $\begin{array}{llll}36855 & 1284 & 1284 & 100 \%\end{array}$ $\begin{array}{llll}36855 & 1284 & 1284 & 100 \%\end{array}$ $\begin{array}{llll}36855 & 1284 & 1284 & 100 \%\end{array}$ $\begin{array}{cccc}36855 & 1284 & 1284 & 100 \% \\ 1408887 & 1284 & 1284 & 100 \%\end{array}$ $\begin{array}{llll}483179 & 1284 & 1284 & 100 \%\end{array}$ $\begin{array}{lllll}36855 & 1279 & 1279 & 100 \%\end{array}$ $\begin{array}{llll}36855 & 1279 & 1279 & 100 \%\end{array}$ $1279-1279-100 \%$

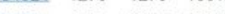
$\begin{array}{lllll}29461 & 715 & 2566 & 100 \%\end{array}$ $\begin{array}{llll}29461 & 715 & 1288 & 100 \%\end{array}$ $\begin{array}{lllll}1171378 & 715 & 1288 & 100 \%\end{array}$ $\begin{array}{lllll}29461 & 715 & 1288 & 100 \%\end{array}$ $\begin{array}{lllll}29461 & 715 & 1288 & 100 \%\end{array}$ $\begin{array}{llll}29461 & 715 & 1288 & 100 \% \\ 29461 & 715 & 1288 & 100 \%\end{array}$

\section{Figure 2}

The analysis of the specific sequence in the B.canis. A. the region of the specific sequence in the genome alignment. B. the alignment of the specific sequences in B.canis and the corresponding sequence in B.melitensis. The red box represents the sequences in C. Red sequences represent the designed primers. C. the alignment of the specific sequence in B.canis and corresponding reverse-complementary sequence in B.melitensis. D. BLAST result of the specific sequence. 


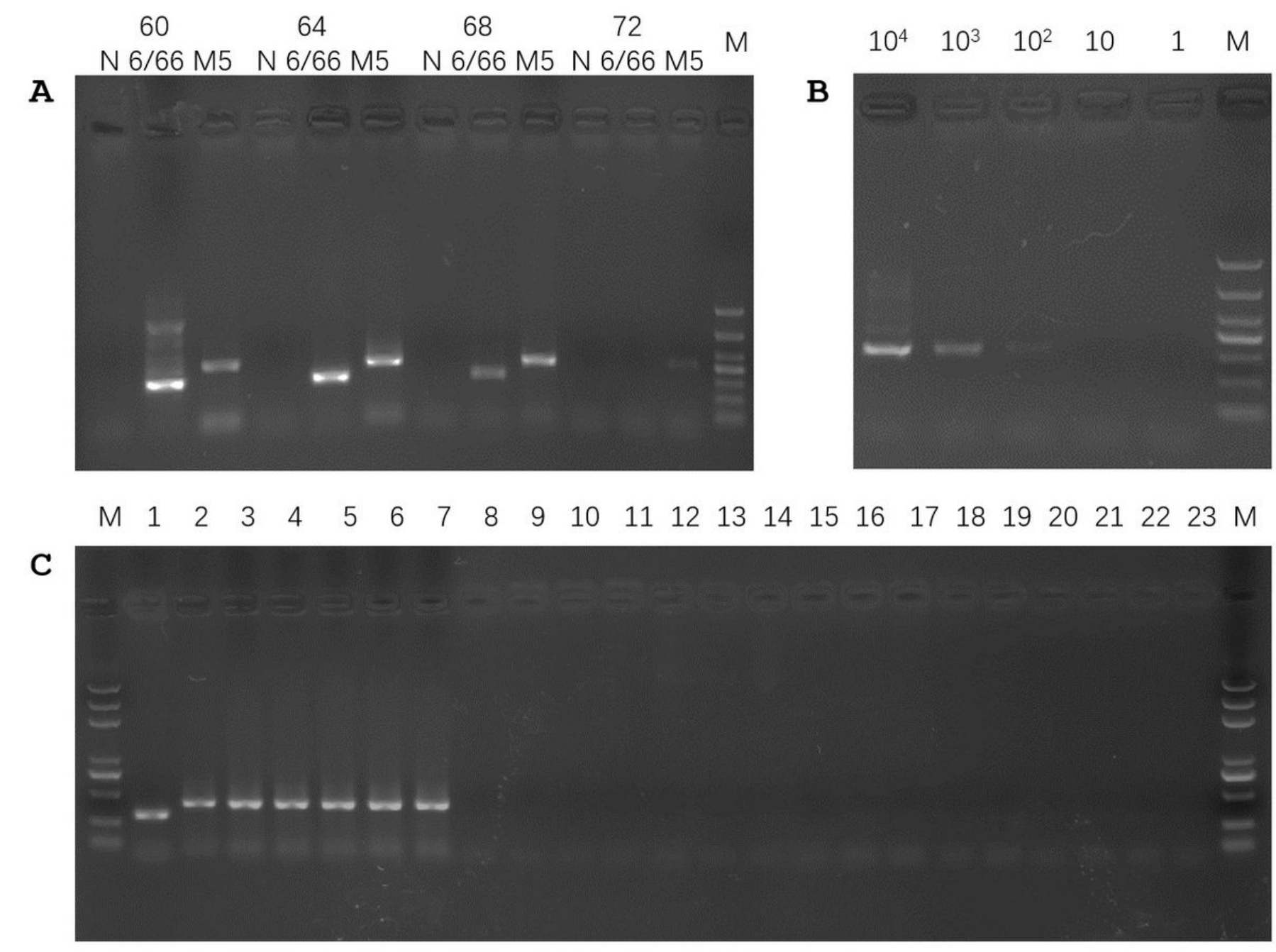

\section{Figure 3}

PCR assay based on the specific sequence. A. Annealing temperature optimization. M, DL1000 DNA Marker. B. Sensitivity assay. M, DL1000 DNA Marker. C. Specificity assay. M, DL2000 DNA Marker; 1, B.canis strain RM6/66; 2, B.abortus strain A19; 3, B.suis strain S2; 4, B.melitensis strain M5; 5, B.abortus strain 2308; 6, B.suis strain 1330; 7, B.melitensis strain 16M; 8, Vanguard® Plus 5-CVL vaccine; 9, Fel-O-Vax® PCT vaccine (Zoetis, USA); 10, E.coli; 11, Salmonella enteritidis; 12 , Shigella dysenteriae; 13 , Pasteurella multocida; 14 , Streptococcus hemolyticus; 15 , Clostridium perfringens type C; 16 , Staphylococcus aureus; 17, Proteus mirabillis; 18, Candida albicans; 19, Streptococcus pyogenes; 20, Streptococcus pneumoniae; 20, Campylobacter jejuni; 21, Listeria monocytogenes; 22, Pseudomonas aeruginosa; 23, negative contral. 


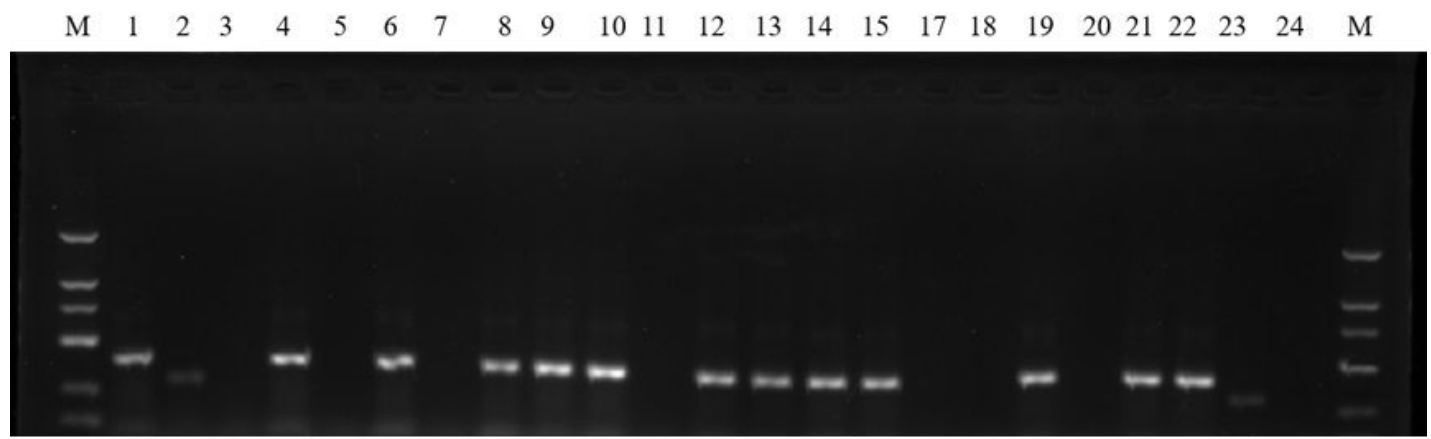

$\begin{array}{lllllllllllllllllllllllll}\text { M } & 25 & 26 & 27 & 28 & 29 & 30 & 31 & 32 & 33 & 34 & 35 & 36 & 37 & 38 & 39 & 40 & 41 & 42 & 43 & 44 & 45 & 46 & 47 & M\end{array}$
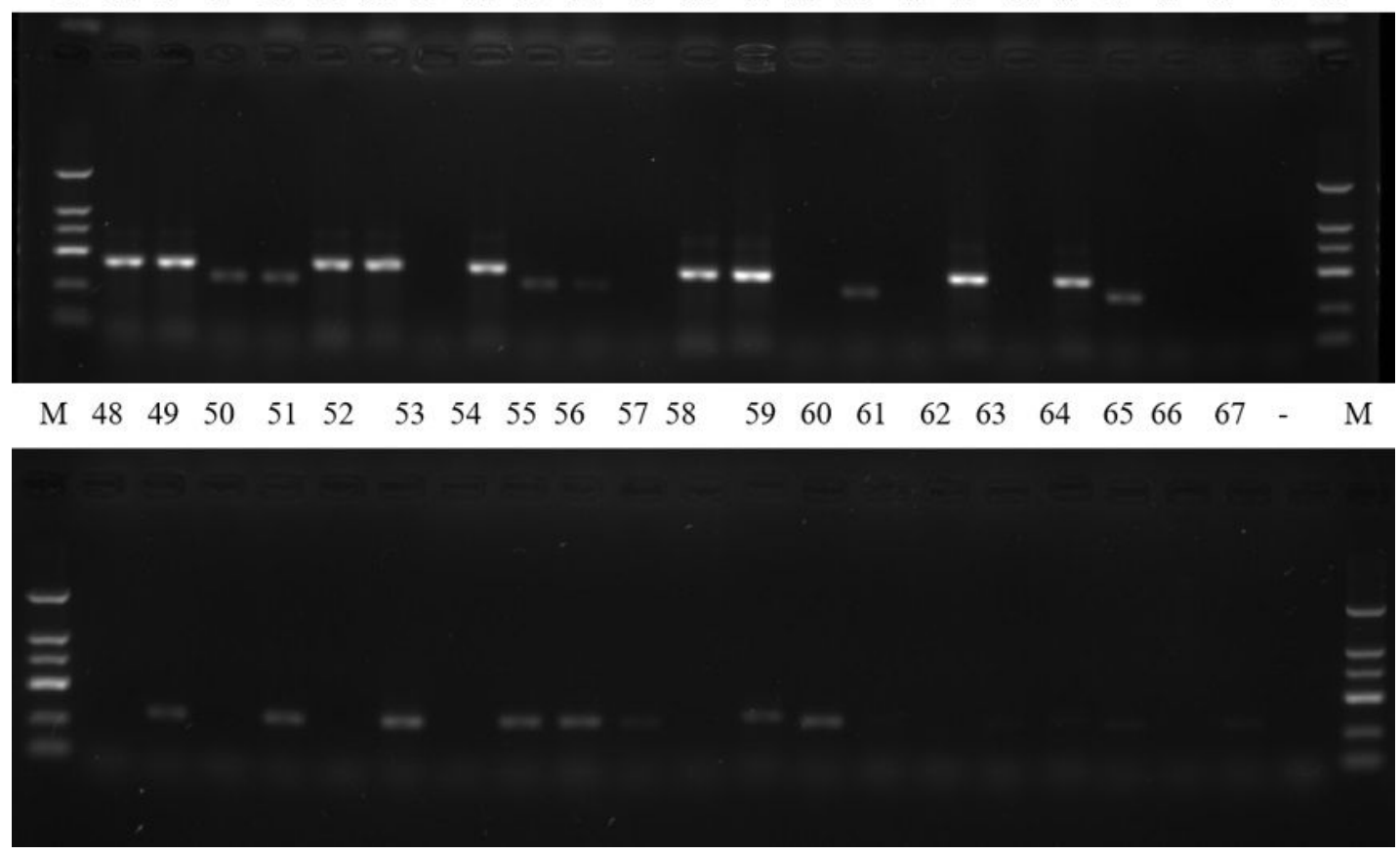

Figure 4

Detection on spiked samples with developed PCR. M, DL2000 DNA Marker; 1-67, DNA samples, NO. 16 missed. 